\title{
What Is the Role of Endoscopic Retrograde Cholangio-Pancreato-Grahy in the Management of Hepatic Hydatid Disease Complications?
}

\author{
Hakima Abid ${ }^{1,2}$, Ghita Ousseur ${ }^{1,2}$, Nada Lahmidani1,2, Mounia El Yousfi ${ }^{1,2}$, Noureddin Aqodad ${ }^{1,2}$, \\ Mohammed El Abkari',2, Adil Ibrahimi1,2, Dafr Allah Benajah ${ }^{1,2}$ \\ ${ }^{1}$ Department of Hepato-Gastro-Enterology, University Hospital Hassan II, Fez, Morocco \\ ${ }^{2}$ Faculty of Medicine, Sidi Mohamed Ben Abdellah University, Fez, Morocco \\ Email: ^abidhakima@hotmail.com
}

How to cite this paper: Abid, H., Ousseur, G., Lahmidani, N., El Yousfi, M., Aqodad, N., El Abkari, M., Ibrahimi, A. and Benajah, D.A. (2020) What Is the Role of Endoscopic Retrograde Cholangio-Pancreato-Grahy in the Management of Hepatic Hydatid Disease Complications?. Open Journal of Gastroenterology, 10, 107-117.

https://doi.org/10.4236/ojgas.2020.105011

Received: March 16, 2020

Accepted: May 24, 2020

Published: May 27, 2020

Copyright $\odot 2020$ by author(s) and Scientific Research Publishing Inc. This work is licensed under the Creative Commons Attribution International License (CC BY 4.0).

http://creativecommons.org/licenses/by/4.0/ (c) (i) Open Access

\begin{abstract}
Liver hydatid cyst is a parasitic disease that is endemic in Morocco. Its gravity is essentially due to its complications, such as Intrabiliary rupture. The aim of our study was to evaluate the role of endoscopic retrograde cholangiopancreatography (ERCP) and endoscopic sphincterotomy in the management of intrabiliary rupture of hydatid disease of the liver. Materials and Methods: This is a retrospective study in the department of Gastroenterology in the University Hospital Hassan II of Fez over a period of 12 years from March 2005 to October 2017. All patients admitted for hepatic hydatid disease and who received ERCP were included. We analyzed the success rate of catheterization of the common bile duct (CBD), the successful clearance of the bile duct and the complications. Results: 2860 patients had received therapeutic ERCP, 151 patients (5.3\%) had hepatic hydatid disease, 112 of which had intrabiliary disruption of hepatic hydatid and 39 patients were admitted for sphincteromy for reversal of the flow after surgery of hydatid cyst. The average age of our patients was 41 years old [12 - 85]. The sex ratio $\mathrm{F} / \mathrm{H}=$ was 1.12. $74 \%(\mathrm{~N}=112)$ patients were admitted to a table cholangitis and $26 \%$ of cases were operated for KHF fistulized in the bile ducts with persistence of a large biliary flow in post-operative (39 cases). The success of initial catheterization of the commun bile duct was achieved for 138 patients (91\%) or obtained secondarily after precut for 13 patients. The evacuation of hydatid membranes was carried out in $51 \%$ of them $(\mathrm{N}=78)$; twenty two (14.5\%) patients had one or more calculations with or without hydatid membranes. A case of gastrointestinal bleeding post ERCP was observed. All the patients followed evolved well in the long term except for two patients who presented in few months after the first ERCP severe cholangitis which required the use
\end{abstract}


of a second ERCP with successful evacuation of membranes. Conclusion: In our study, endoscopic management of hydatid cyst remains a dominant position, with a very satisfactory success rate and an acceptable rate of morbidity and mortality.

\section{Keywords}

Hydatid Cyst, Intrabiliary Rupture, Complications, Endoscopic Retrograde Cholangiopancreatography, Endoscopic Sphincterotomy

\section{Introduction}

Hepatic hydatid disease is a worldwide public health issue, essentially in countries like Morocco with a high endemic rate [1] [2] [3]. Rupture into biliary tract is a common complication and varies between 5\% and 25\% [4] [5] [6] [7]. For a long time the treatment of this complication has been surgical with $35 \%$ to $60 \%$ morbidity and $2 \%$ to $13 \%$ mortality rates. Hence the advent of endoscopic treatment with the first case of biliary complication treated endoscopically in 1985 was realised by El Karawi [8] [9]. Since then, several series report the interest of the ERCP as a non-invasive or mini-invasive method for the treatment of complicated hydatid cyst whether in pre- or post-operative. The aim of this study was to present our experience on the effectiveness of endoscopic treatment modalities in cases of biliary complications of hepatic hydatid cysts.

\section{Materials and Methods}

It is a descriptive and analytical retrospective study within the Department of Gastroenterology of the University Hospital of Fez over a period of 12 years [March 2005-October 2017]. All patients who had received ERCP for hydatid cyst of the liver in pre-operative for cholangitis +/- pancreatitis or in postoperative for persistent post-operative biliary fistula were included. Patients under 12 years of age were excluded. Diagnosis of acute cholangitis was based on clinical criteria (jaundice + fever), biological (cholestasis) and radiological criteria (abdominal ultrasound $+/$ - computed tomography CT or MRI). Based on ERCP data, we analyzed the success rate of catheterization of the CBD, the successful clearance of the CBD and the complications such as bleeding and post ERCP pancreatitis.

\section{Results}

Over the period studied, 2860 ERCP were performed. In 151 cases, the indication was represented by a complicated hydatid cyst of the liver bile ducts. It represented $5.3 \%$ of the indications for ERCP in our series. The average age of patients was 41 years with a range of 12 to 85 years old, there was a slight female predominance with a sex ratio $\mathrm{F} / \mathrm{H}$ 1.2. A previous history of cholecystectomy 
was found for 17 patients, eight patients were known carrier of asymptomatic hepatic hydatid cyst (KHF) and 49 patients were operated for hydatic cyst. one hundred and twelve patients (74\%) were admitted for cholangitis, of which 91 patients were presented with non-severe cholangitis with three criteria jaundice with pain and fever, 12 patients had severe cholangitis found on clinicopathologic plan involving thrombocytopenia and/or renal failure and clinical disorders of consciousness and/or septic shock requiring intensive care unit and 9 patients had an acute pancreatitis associated to cholangitis. Twenty six percent (39 cases) of cases were operated for KHF fistulized in the bile ducts with persistence of a large biliary flow in post-operative (Table 1).

Among these patients, we had 6 cases of biliptysis associated due to a bronchocystobiliary fistula that were diagnosed by radiology, five of them have benefited from an ERCP initially and the 6th patient in postoperatively to reverse the bile flow into the duodenum.

Biological results showed that $87 \%$ of patients had cholestasis associated or not to cytolysis. Thrombocytopenia was found in 4 patients associated with renal insufficiency in 7 patients. Twelve patients had received a dosage of lipase to the atypical clinical symptoms of cholangitis table with a predominantly gastric pain, the dosage revealed a lipase level greater than 3 indicating a normal pancreatitis.

Radiological evaluation including an abdominal ultrasound performed in 124 patients (82\%), abdominal CT in 51 patients (34\%) and MRI in 9 cases (6\%). They objectified dilation of the common bile duct in 102 cases (68\%), dilation of the intra-hepatic biliary duct in 84 cases (56\%), fistulized hydatid cyst of the liver in 107 cases (71\%), highlighting of calculations in 6 cases, and enormous hydatid cyst compressing the main bile duct at the level of the hilum in 2 patients, one of them had secondary portal hypertension (Table 2) (Figure 1, Figure 2).

The success of initial catheterization of the CBD was achieved for 138 patients (91\%), or obtained secondarily after precut in 13 cases $(9 \%)$. The use of balloon

Table 1. Clinical characteristics.

\begin{tabular}{lc}
\hline \multicolumn{1}{c}{ Clinical characteristics } & Results \\
\hline Total number of patients & $\mathrm{N}=151$ \\
Average age & 41 years $[12,85]$ \\
Sex-ratio F/M & 1.2 \\
Previous history of: & \\
- Cholecystectomy & $17(11 \%)$ \\
- surgery for Hepatic hydatid cyst & $49(32 \%)$ \\
Cholangitis & $112(74 \%)$ \\
- Non-severe cholangitis & $91(60 \%)$ \\
- severe cholangitis & $12(8 \%)$ \\
- Pancreatitis & $9(6 \%)$ \\
Persistence of a large biliary flow in post-operative & $39(26 \%)$ \\
\hline
\end{tabular}




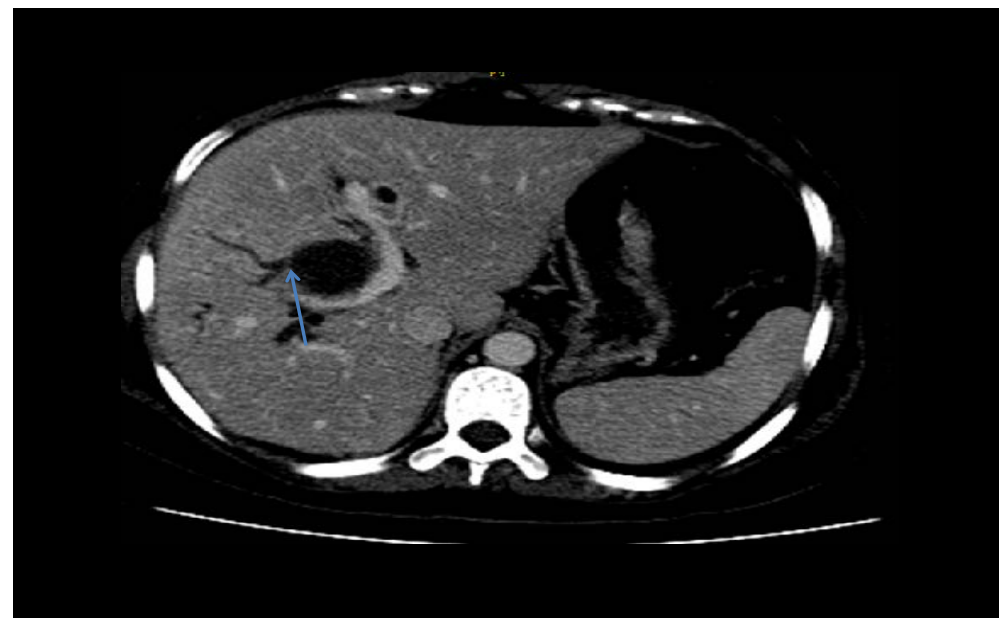

(a)

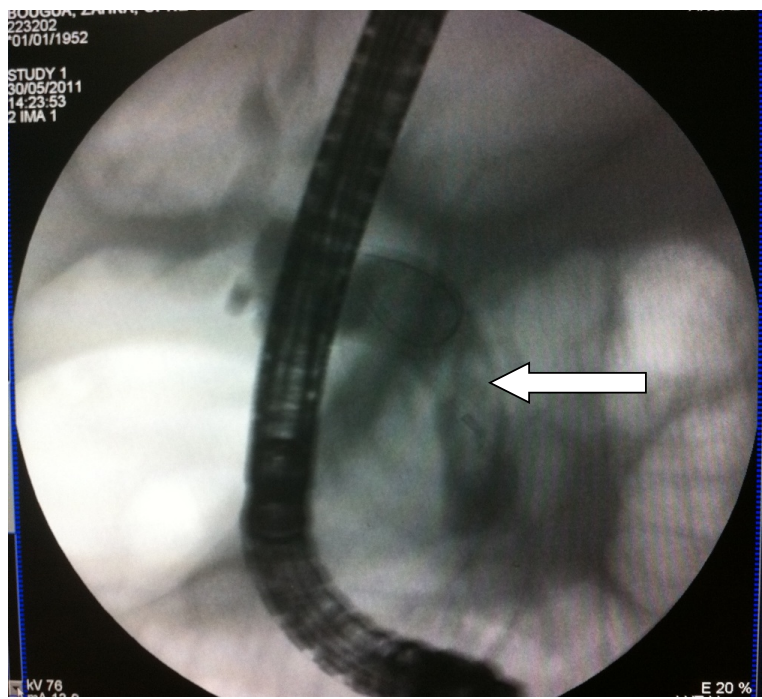

(b)

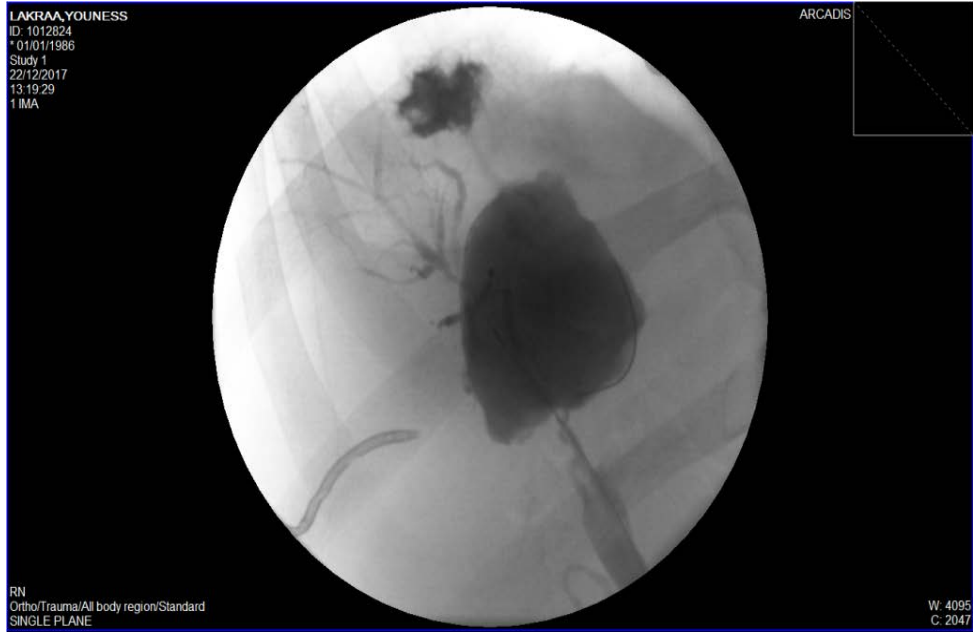

(c)

Figure 1. (a) CT scan showing a fistulized hydatid cyst in the bile ducts (blue arrow); (b) Images gaps in fluoroscopy after opacification of the CBD; (c) Guide-wire wrapped in the cystic cavity in fluoroscopy after opacification. 


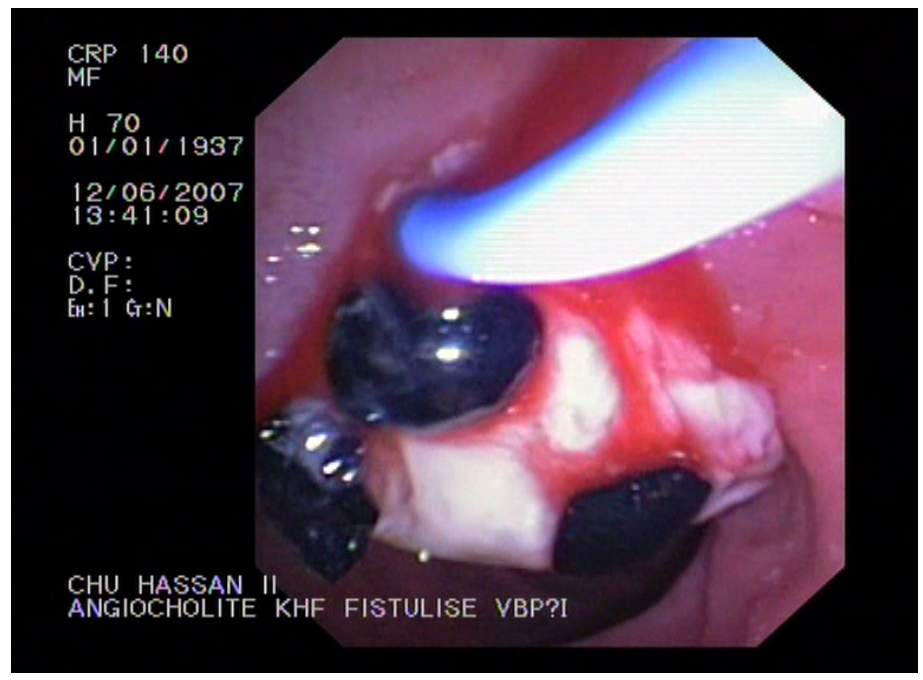

Figure 2. Derived from calculations with hydatid membranes by sphincterotomy.

Table 2. Radiological characteristics.

\begin{tabular}{cc}
\hline radiological characteristics & Results (N=38) \\
\hline abdominal ultrasound & $124(82 \%)$ \\
abdominal CT & $51(34 \%)$ \\
Expansion of the CBD & $102(68 \%)$ \\
Expansion of intra hepatic duct & $84(56 \%)$ \\
Dense Material & $107(71 \%)$ \\
Evocative image of hepatic hydatid cyst & $151(100 \%)$ \\
Obstacle gallstone + dense material of the CBD & $6(4 \%)$ \\
Pancreatitis & $9(6 \%)$
\end{tabular}

to release the bile duct was performed successfully in 132 cases while we needed the dormia in 15 cases. In preoparative for cholangitis, the evacuation of hydatid membranes (Figure 3, Figure 4) with CBD release was achieved in $62.5 \%$ of the cases $(\mathrm{N}=70), 9$ patients $(8 \%)$ had calculations associated hydatid membranes (Figure 3 ) and twenty two patients (19\%) had one or more calculations. No hydatid material was found in $11 \%(\mathrm{~N}=10)$ of the patients. In post operative, 8 patients (20\%) had hydatid membranes while CBP was free in $80 \%$ of cases ( $\mathrm{n}=$ 31) (Table 3, Figure 5). The use of biliairy prosthesis was necessary in 3 cases including 2 cases with enormous hydatid cyst compressing the main bile duct at the level of the hilum.

After ERCP, nineteen patients (17\%) underwent surgery with resection of the prominent dome while ERCP alone was sufficient in other cases with good evolution $(83 \%)$. For patients who maintained significant postoperative bile flow, endoscopic sphincterotomy ES was sufficient to reverse bile flow ++ in all cases.

In our series, two complications of ERCP were observed:

- A case of gastrointestinal bleeding made of post ERCP, the upper endoscopy objectified ulcer of genus superus with good evolution. 

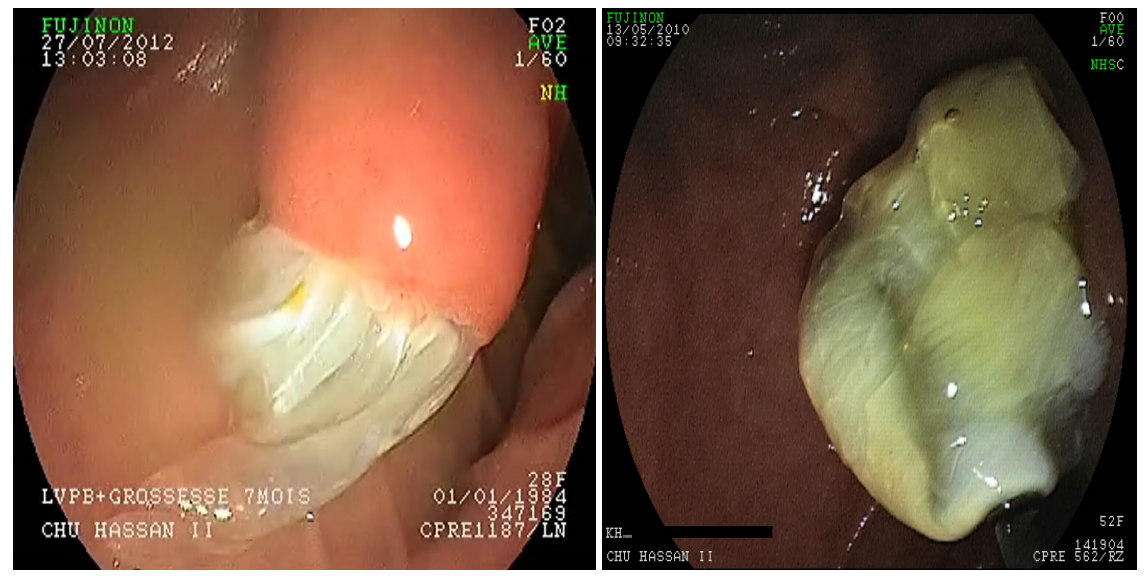

Figure 3. Hydatid membranes from the papilla.
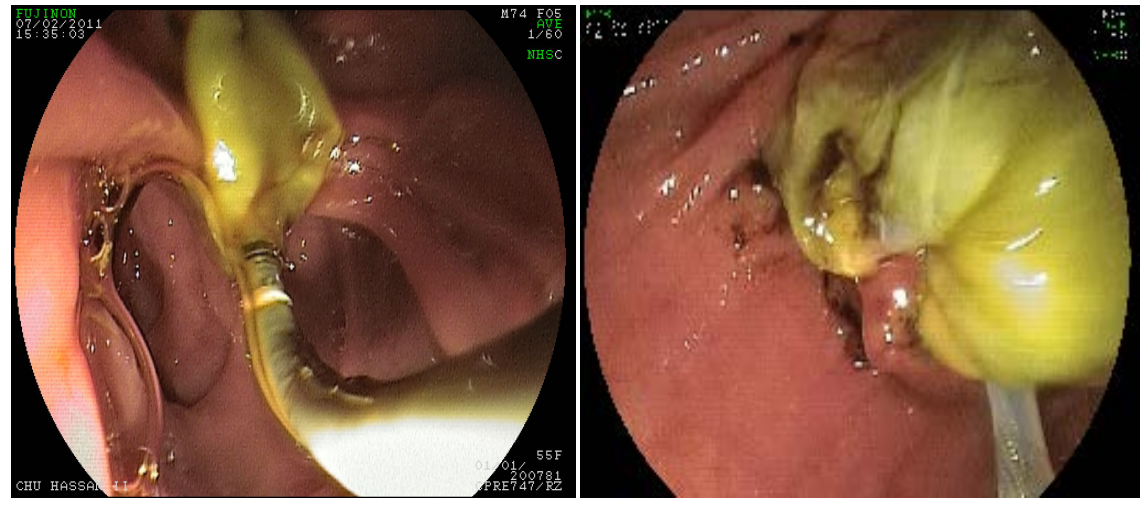

Figure 4. Evacuation of hydatid membranes per ERCP.

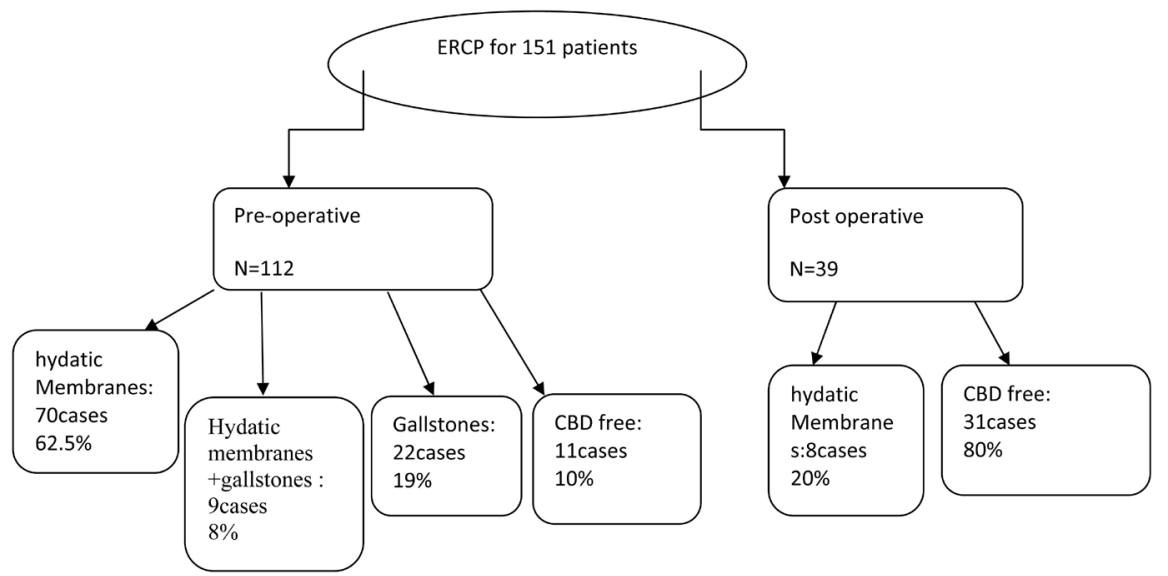

Figure 5. Results of ERCP.

- A case of post ERCP pancreatitis with also good evolution.

Three deaths by septic shock were deplored including one inoperable patient and two in post operative.

In the long term, 4 patients, few months after the first ERCP, required the use of a 2nd ERCP successfully: two of them presented cholangitis and ERCP evacuated hydatid membranes with release of the bile duct, the $3 \mathrm{rd}$ case had presented a 
Table 3. Results of ERCP.

\begin{tabular}{cc}
\hline Data ERCP & Results \\
sphincterotomy & $151(100 \%)$ \\
Expansion of the CBD: & $107(71 \%)$ \\
Evacuation of hydatid membranes \\
without gallstones & $78(51 \%)$ \\
Hydatic membranes with calculation & $9(6 \%)$ \\
Gallstones only & $22(15 \%)$ \\
CBD free & $42(28 \%)$ \\
Use of biliairy prothesis & $3(1.9 \%)$ \\
Immediate complications: bleeding & $1(0.66 \%)$ Ulcer genus superiorus stage IIc \\
Post ERCP pancreatitis & $1(0.66 \%)$ \\
Second ERCP for severe cholangitis, \\
with evacuation of hydatid membranes
\end{tabular}

superinfection of the residual cavity after surgery and required an enlargement of the sphincterotomy, the last patient had an enormous hydatid cyst with portal hypertension had required an ERCP with placement of biliary prosthesis.

\section{Discussion}

Hydatid disease is endemic in most parts of the world, especially in the Mediterranean where sheep husbandry is common, and is an important medical health problem in these regions, seen mostly in South America, North Africa, the Middle East and Eastern Europe [10]. In Morocco, the disease is endemic, an incidence of 4.55 cases operated per 100,000 inhabitants, which puts Morocco in third position in the Maghreb after Tunisia and Algeria [11]. KH can sit in any part of the body, but hepatic localization remains the most common (70\%), followed by pulmonary involvement ( $10 \%$ to $40 \%)$. The discovery of hepatic hydatid cyst is in most cases at the stage of complications [12]. These complications are dominated by fistulae hydatid cyst into the biliary tract [6]-[13]. This rupture into the biliary tract is responsible for acute cholangitis for $82 \%-87 \%$ of the cases and severe for 32\% - 36\% of cases (septic shock, renal failure), which joins the data from our series. In fact $74 \%$ patients were presented in a non-serious table cholangitis and $26 \%$ in serious table.

Acute pancreatitis hydatid origin is a rare complication, which is in the pathogenesis of biliary pancreatitis part of a canal passing mechanism with parasite material through kysto-biliare fistula and transient obstruction of the papilla [14]. In our series we had 12 cases of acute pancreatitis. The diagnosis of pancreatitis hydatid origin was confirmed with endoscopic sphincterotomy for removal of hydatid membranes.

In addition to rupture in the bile ducts, the hydatid cyst can simultaneously rupture in the bronchi and give biliptysis or hydatid vomica, this bronchocysto- 
biliary fistula has been described for the first time in 1850 by Peacock TB, it was complicating hydatid cystic disease of the liver [15]. In our series, we had 6 cases of bronchocystobiliary fistula and who have benefited from an ERCP with good evolution.

The most useful methods of diagnosis in our series were the ultrasound and the computed tomography of the abdomen. The presence of a dilated common bile duct, in addition to a cystic lesion of the liver is strongly suggestive of a hydatid cyst ruptured into the biliary tract [3] [16] [17]. Although ERCP can be used as a diagnostic method, it is better to use it as a therapeutic method.

The standard treatment of uncomplicated hydatid cyst is the radical surgery (pericystectomy or hepatic resection) [18]. Before the widespread use of ERCP, the treatment for hydatid disease with rupture into the biliary tract was surgery for exploration of the biliary tract with choledochotomy and placement of a $\mathrm{T}$ tube for the cyst remnants. This surgical treatment has a significant rate of complications with a mortality rate of $4.5 \%$ in the range of Zaouch et al. [9]. Currently, ERCP is the first choice of treatment.

Preoperative therapeutic ERCP has a reported success rate as high as $80 \%$ $100 \%$ [19] [20] [21], and can be used when cystobiliary communication or hydatid membranes and/or daughter cysts that cause biliary obstruction are demonstrated by cholangiography. In major ruptures, hydatid material encountered in bile ducts can be emptied out by ES, and a Dormia basket and biliary occlusion balloon can be used to clean out the common and main bile ducts. In our series, to clean out the CBP we used balloon in 137 cases, dormia basket in 15 cases, while we used both balloon and dormia basket in 4 cases. We have also used biliairy prosthesis in 3 cases.

The endoscopic management of biliary fistula is an innovative treatment that has already shown its effectiveness and safety. No serious complications have been described after endoscopic drainage. In our series, the use of ERCP in the treatment of hydatid cyst was successful in $100 \%$, we had one case of gastrointestinal bleeding post ERCP and another case of pancreatitis was noted with very good evolution.

Post-operative biliary fistulas are unavoidable, constituting the most frequent complication after surgery for hepatic hydatid disease with persistent external drainage in which there is communication between the residual cyst and biliary tree. Surgery has been the traditional treatment for biliary fistulas because of the hydatid cysts that fail to close spontaneously. However, because of the presence of adhesions and inflammation, surgery may be difficult and hazardous. ES should be of great benefit because it facilitates continuous biliary flow by decreasing the duodenobiliary pressure gradient [9] [22] [23] [24]. The success rate is reported to be $70 \%$ to $100 \%$, with an overall rate of fistula closure of $81 \%$ in 10 to 20 days [25]. In our series, ERCP was successful in all cases (100\%) and closure of the fistula is obtained within an average of 7 days ( 1 - 15 days).

Another post-operative complication is the Infection and/or abscess formation that may occur after colonization of the ruptured cavity through the exter- 
nal cystobiliary fistula by common intra-abdominal pathogens [26]. In this study we deplored one case of abscess which benefited from percutaneous drainage with enlargement of the SE, the evolution was good under antibiotherapy associated.

Regarding the patient's rapid clinical improvement, as well as high surgical risk, no further intervention was considered necessary. Thus, endoscopy, although sparsely used as monotherapy, proved to be therapeutic. There are numerous studies demonstrating the effectiveness of the use of ERCP to clean out bile ducts and cystic materials during successive follow-ups and $25 \%$ of patients are cured and do not need any further surgical treatment [27]. In the present series, ERCP was sufficient in $83 \%$ and only nineteen patients (17\%) had surgery.

\section{Conclusion}

The results of our study are consistent with those of the literature and confirm once again that ERCP with ES proved to be a choice offering excellent immediate and short-term post-procedure results with an acceptable rate of morbidity without mortality. Thus, it may be proposed alternatively, especially if surgical risk is high and clinical benefit adequate.

\section{Conflicts of Interest}

The authors declare no conflicts of interest regarding the publication of this paper.

\section{References}

[1] Ulualp, K., Aydemir, I., Senturk, H., Eyuboglu, E., Cebeci, H., Unal, G. and Unal, H. (1995) Management of Intrabiliary Rupture of Hydatid Cyst of the Liver. World Journal of Surgery, 19, 720-724. https://doi.org/10.1007/BF00295913

[2] Langer, B. (1987) Surgical Treatment of Hydatid Disease of Liver. British Journal of Surgery, 74, 237-238. https://doi.org/10.1002/bjs.1800740403

[3] Murty, T.V.M., Sood, K.C. and Rakas, F.S. (1989) Biliary Obstruction Due to Ruptured Hydatid Cyst. Journal of Pediatric Surgery, 24, 401-403. https://doi.org/10.1016/S0022-3468(89)80281-7

[4] Singh, V., Reddy, D.C., Vernma, G.R. and Singh, G. (2006) Endoscopic Management of Intrabiliary-Ruptured Hepatic Hydatid Cyst. Liver International, 26, 621-624. https://doi.org/10.1111/j.1478-3231.2006.01259.x

[5] Kumar, R., Reddy, S.N. and Thulkar, S. (2002) Intrabiliary Rupture of Hydatid Cyst: Diagnosis with MRI and Hepatobiliary Isotope Study. The British Journal of Radiology, 75, 271-274.

[6] Vignote, M.L., Mino, G., de la Mata, M., de Dios, J.F. and Gomez, F. (1990) Endoscopic Sphincterotomy in Hepatic Hydatid Disease Open to the Biliary Tree. British Journal of Surgery, 77, 30-31. https://doi.org/10.1002/bjs.1800770110

[7] Ergüney, S., Tortum, O., Taspinar, A.H., Ertem, M. and Gazioglu, E. (1991) Les kystes hydatiques compliqués du foie. Annales de Chirurgie, 45, 584-589.

[8] Mohamed, A.E., Al Karawi, M.A. and Yasawy, M.I. (1991) Modem Techniques in the Diagnosis and Treatment of Gastrointestinal and Biliary Tree Parasites. Hepa- 
to-Gastroenterology, 38, 180-188.

[9] Zaouch, A., Haouet, K., Jouini, M., El Hachaichi, A. and Dziri, C. (2001) Management of Liver Hydatid Cysts with a Large Biliocystic Fistula: Multicenter Retrospective Study. Tunisian Surgical Association. World Journal of Surgery, 25, 28-39. https://doi.org/10.1007/s002680020005

[10] Eckert, J. and Deplazes, P. (2004) Biological, Epidemiological, and Clinical Aspects of Echinococcosis, a Zoonosis of Increasing Concern. Clinical Microbiology Reviews, 17, 107-135. https://doi.org/10.1128/CMR.17.1.107-135.2004

[11] Belamalem, et al. (2014) Epidémiologie de l'hydatidose dans la Région du Gharb (Chrarda Beni Hssen) Maroc. Antropo, 31, 33-37. http://www.didac.ehu.es/antropo

[12] Abi, F., et al. (1988) Les Kystes Hydatiques du foie. A propos de 181 cas dont 150 compliqués. Lyon Chirurgical, 84, 418-420.

[13] Barros, J.L. (1978) Hydatid Disease of the Liver. The American Journal of Surgery, 135, 597-600. https://doi.org/10.1016/0002-9610(78)90043-0

[14] Dawson, J.L., Stamatakis, J.D., Stringer, M.D. and Williams, R. (1988) Surgical Treatment of Hepatic Hydatid Disease. British Journal of Surgery, 75, 946-950.

[15] Rabbani, K., et al. (2010) Pancréatite aiguë secondaire à une compression extrinsèque du wirsung par un kyste hydatique rétropéritonéale. Journal African d Hépato-Gastroentérologie, 4, 257-259. https://doi.org/10.1007/s12157-010-0198-2

[16] Peacock, T.B. (1850) Case in Which Hydatids Were Expectorated and One of Suppuration of Hydatid Cyst of the Liver Communicating with the Lungs. Edinburgh Medical Journal, 74, 33-46. https://doi.org/10.1002/bjs.1800751004

[17] Alper, A., Arıogul, O., Emre, A., Uras, A. and Okten, A. (1987) Choledochoduodenostomy for Intrabiliary Rupture of Hydatid Cyst of the Liver. British Journal of Surgery, 74, 243-245. https://doi.org/10.1002/bjs.1800740405

[18] WHO Informal Working Group (1996) Guidelines for Treatment of Cystic and Alveolar Echinoccocosis in Humans on Echinoccocosis. Bulletin of the World Health Organization, 74, 231-242.

[19] Becker, K., Frieling, T., Saleh, A. and Häussinger, D. (1997) Resolution of Hydatid Liver Cyst by Spontaneous Rupture into the Biliary Tract. Journal of Hepatology, 26, 1408-1412. https://doi.org/10.1016/S0168-8278(97)80479-5

[20] Dolay, K., Soylu, A., Yanar, H., Aygun, E. and Ertekin, C. (2007) Management of Intrabiliary Rupture of Hepatic Hydatid Cysts with Endoscopic Nasocystic Drainage. 15th United European Gastroenterlogy Week (UEGW), Paris, 27-31.

[21] Rodriguez, A.N., Sánchez del Río, A.L., Alguacil, L.V., De Dios Vega, J.F. and Fugarolas, G.M. (1998) Effectiveness of Endoscopic Sphincterotomy in Complicated Hepatic Hydatid Disease. Gastrointestinal Endoscopy, 48, 593-597. https://doi.org/10.1016/S0016-5107(98)70041-0

[22] Al Karawi, M.A., Yasawy, M.I. and el Shiekh Mohamed, A.R. (1991) Endoscopic Management of Biliary Hydatid Disease: Report on Six Cases. Endoscopy, 23, 278-281. https://doi.org/10.1055/s-2007-1010686

[23] Akkiz, H., Akinoglu, A., Colakoglu, S., Demryurek, H. and Yagmur, O. (1996) Endoscopic Management of Biliary Hydatid Disease. Canadian Journal of Surgery, 39, 287-292.

[24] Ponchon, T., Bory, R. and Chavaillon, A. (1987) Endoscopic Retrograde Cholangiography and Sphincterotomy for Complicated Hepatic Hydatid Cyst. Endoscopy, 19, 174-177. https://doi.org/10.1055/s-2007-1018274 
[25] Simsek, H., Ozaslan, E., Sayek, I., et al. (2003) Diagnostic and Therapeutic ERCP in Hepatic Hydatid Disease. Gastrointestinal Endoscopy, 58, 384-389. https://doi.org/10.1067/S0016-5107(03)00013-0

[26] Lewall, D.B. and McCorkell, S.J. (1986) Rupture of Echinococcal Cysts: Diagnosis, Classification, and Clinical Implications. American Journal of Roentgenology, 146, 391-394. https://doi.org/10.2214/ajr.146.2.391

[27] Dolay, K., et al. (2014) ERCP and Hydatid Disease. World Journal of Gastroenterology, 20, 15253-15261. https://doi.org/10.3748/wjg.v20.i41.15253 